\title{
Lioubov Savova, Le Métier du poète en exil. Vladimir Nabokov
}

\section{Pierangela Adinolfi}

\section{Q OpenEdition}

1 Journals

\section{Edizione digitale}

URL: https://journals.openedition.org/studifrancesi/3263

DOI: $10.4000 /$ studifrancesi.3263

ISSN: 2421-5856

\section{Editore}

Rosenberg \& Sellier

\section{Edizione cartacea}

Data di pubblicazione: 1 juillet 2013

Paginazione: 504

ISSN: 0039-2944

\section{Notizia bibliografica digitale}

Pierangela Adinolfi, «Lioubov Savova, Le Métier du poète en exil. Vladimir Nabokov», Studi Francesi

[Online], 170 (LVII | II) | 2013, online dal 30 novembre 2015, consultato il 02 février 2023. URL: http:// journals.openedition.org/studifrancesi/3263 ; DOI: https://doi.org/10.4000/studifrancesi.3263

Questo documento è stato generato automaticamente il 2 février 2023.

\section{(c) (1) (9)}

Creative Commons - Attribuzione - Non commerciale - Non opere derivate 4.0 Internazionale - CC BYNC-ND 4.0

https://creativecommons.org/licenses/by-nc-nd/4.0/ 


\title{
Lioubov Savova, Le Métier du poète en exil. Vladimir Nabokov
}

\author{
Pierangela Adinolfi
}

\section{NOTIZIA}

LIOUBov SAvova, Le Métier du poète en exil. Vladimir Nabokov, Elias Canetti et Yordan

Yovkov, Paris, Champion, 2012, pp. 631.

1 Nel presente e poderoso volume, versione ridotta della tesi di dottorato discussa dall'autrice alla Sorbonne Nouvelle nel settembre del 2007, è analizzato il grande tema «écriture et déracinement» nell'opera di tre illustri «Européens» del xx secolo: Nabokov, Canetti e Yovkov. Cogliere «l'espace littéraire de l'exil» nei tre autori, al di là di ciò che Nabokov definiva «l'expression facile de la nostalgie», è l'intento della Savova, il cui imponente lavoro è così ripartito: il Prologue, «Le Métier du poète en exil» (pp. 13-31), le tre sezioni comprendenti undici capitoli, la Conclusion, «Le regard dépaysé. Un Horizon permanent» (pp. 595-602), la Bibliografia e l'Indice dei nomi.

La prima sezione, intitolata «La part du refus chez l'écrivain en exil», comporta tre capitoli. Nel capitolo I, «Le Chien de son temps» (pp. 35-72), l'autrice affronta il tema dell'identità artistica in relazione al determinismo storico ed in particolare si sofferma su La Conscience des Mots di Canetti, su «Le Péché d'Ivan Béline» di Yovkov e Intransigeances e La Vraie vie de Sebastian Knight di Nabokov. Nel capitolo II, «Sous le signe de Peter Schlemihl» (pp. 73-121), vengono analizzate le differenti modalità dell'esilio e le soggettive reazioni degli scrittori. I testi principalmente commentati sono: di Yovkov, Chroniques 1912-1918; di Nabokov, Autres rivages e La Défense Loujine; di Canetti, La langue sauvée. Nel capitolo III, «Scène vide, lumière tamisée» (pp. 123-167), l'autrice indica il percorso che va dall'esilio fattuale allo sradicamento più intimo e privato e che conduce gli autori al tentativo dell'autobiografia. I temi trattati sono gli anni rumeni di Yovkov e le autobiografie di Nabokov e di Canetti. 
La seconda sezione s'intitola "Le rêve d'Ithaque. Fin d'un topos et invitation au voyage» e include i tre capitoli successivi. Nel capitolo IV, «Le Désir d'absence» (pp. 171-218), la Savova si sofferma sull'importante processo di elaborazione del lutto da separazione e sul fecondo tentativo di procedere alla scrittura del libro. Gli argomenti sono: Yovkov, Légendes de la Stara Planina; Canetti, Le Flambeau dans l'oreille; Nabokov, Le don, Intransigeances e Autres rivages. Nel capitolo V, «La Maison interdite» (pp. 219-277), vengono considerati la difficoltà e lo spaesamento del ritorno che diventa impossibile. Argomenti: Canetti, Autodafé e Nabokov, La Défense Loujine. Nel capitolo VI, «Une poignée de lumières au loin» (pp. 279-330), viene analizzata la nascita del sentimento del «foyer» nello stato di allontanamento. I temi privilegiati sono: Nabokov, L'Exploit; Canetti, Les Voix de Marrakech; Yovkov, «La Plainte du berger».

La terza ed ultima sezione, intitolata «Pour une perception migrante de l'espace et de l'être», comprende cinque ulteriori capitoli: nel capitolo VII, «Les Frontières intérieures» (pp. 333-392), viene presa in considerazione la varia tipologia dell'atteggiamento xenofobo ed i risultati letterari delle «fausses rencontres» fra «étrangers». Sono esaminati i temi riguardanti Sebastian Knight e Mademoiselle O di Nabokov, Ginette e Élie Dahan di Canetti, Bojoura di Yovkov. Nel capitolo VIII, «Identités en métamorphose» (pp. 393-437), oggetto di riflessione è l'incertezza identitaria, l'oscillazione dei significati all'interno del testo letterario. Gli argomenti affrontati sono: Nabokov, Le Don; Canetti, Le Territoire de l'homme e Les Voix de Marrakech; Yovkov, «La Garde la plus sûre» e «Têtes de héros». Nel capitolo IX, «L'Homme sur le seuil» (pp. 440-472), sono messe in luce le figure dell'«enracinement» desiderato e compromesso. I temi prioritari riguardano Chibil e Indjé di Yovkov e la «signature cryptée» di Nabokov in La Vraie vie de Sebastian Knight. Nel capitolo X, «La Mélancolie prospective du poète» (pp. 473-521), l'autrice concentra la sua attenzione sui luoghi, sulla figura del padre e sul Leitmotiv dell'assenza. I principali testi analizzati sono La Langue sauvée e Le Flambeau dans l'oreille di Canetti e L'Exploit, Le Don e Autres rivages di Nabokov. Nel capitolo XI, l'ultimo, «La Poterie de Menton» (pp. 523-594), la Savova trasferisce la percezione dello spostamento e dell'allontanamento dalla soggettività dello scrittore allo spazio circostante. I testi esaminati sono: Machenka, Le Don e Autres rivages di Nabokov; Le Flambeau dans l'oreille di Canetti; Légendes de la Stara Planina di Yovkov. 